DEPARTAMENTO DE ADMINISTRAÇÃO

TRABALHO DE CONCLUSÃO DE CURSO

\title{
ANÁLISE DA PERCEPÇÃO DOS COLABORADORES ACERCA DAS MUDANÇAS PROVOCADAS PELA CRIAÇÃO DA UNIVERSIDADE CORPORATIVA EM UMA INSTITUIÇÃO FINANCEIRA.
}




\section{Maria de Fátima Bruno de Faria - Doutora}

"Trabalho apresentado em cumprimento às exigências acadêmicas parciais da disciplina Estágio Supervisionado em administração para a obtenção do grau de Administrador" 
FREITAS, Alexandre M.

Análise da percepção dos colaboradores acerca das mudanças provocadas pela criação da Universidade Corporativa em uma Instituição Financeira.

Monografia (graduação) - Universidade de Brasília, Departamento de Administração, 2009.

Orientador: Maria de Fátima Bruno de Faria, Dr.

1. Conhecimento organizacional. 2. Universidade Corporativa. 3. Percepção de mudança. 
Universidade de Brasília

Faculdade de Economia, Administração, Contabilidade e Ciências da Informação e Documentação

DEPARTAMENTO DE ADMINISTRAÇÃO

\section{ANÁLISE DA PERCEPÇÃO DOS COLABORADORES ACERCA DAS MUDANÇAS PROVOCADAS PELA CRIAÇÃO DA UNIVERSIDADE CORPORATIVA EM UMA INSTITUIÇÃO FINANCEIRA.}

A Comissão Examinadora, abaixo identificada, aprova o Trabalho de Conclusão do Curso de Administração da Universidade de Brasília do aluno

ALEXANDRE MATTOS DE FREITAS

Maria de Fátima Bruno de Faria, Doutora

Professor-Orientador

Pedro Meneses, Doutor

Professor-Examinador

Professor-Examinador

Brasília, 07 de julho de 2009 
Dedico esse trabalho aos meus pais Edimar Borges de Freitas e Érika Nunes de Mattos e ao meu irmão Eduardo Mattos de Freitas pelo apoio e carinho demonstrados ao longo de toda minha vida. 
Agradeço à organização pesquisada por ter criado condições para que a pesquisa pudesse ter sido realizada.

A todos aqueles que com presteza responderam aos questionários e colaboraram para o sucesso do estudo.

À orientadora Maria de Fátima Bruno de Faria pela paciência e atenção dispensadas a mim durante essa jornada.

A todos os professores que colaboraram direta ou indiretamente para a conclusão desse trabalho. 
"O conhecimento é em si mesmo um poder."

Francis Bacon 
O presente trabalho tem como objetivo geral avaliar, por meio da percepção dos funcionários de uma Instituição Financeira, o funcionamento de sua Universidade Corporativa (UC). O conceito adotado no estudo para UC é o de Meister (1999, p.29), que a define como "um guarda-chuva estratégico para desenvolver e educar funcionários, clientes, fornecedores e comunidade, a fim de cumprir as estratégias empresariais da organização". Foi realizada uma pesquisa descritiva, envolvendo a utilização da abordagem qualitativa e quantitativa. A primeira foi feita por meio da análise documental para verificar o que a alta administração busca com a UC, e a segunda se deu com a aplicação de questionários validados estatisticamente junto aos colaboradores de uma agência bancária dessa Instituição. O resultado da análise de documentos apontou que o objetivo da UC é ser percebida pelos funcionários como um importante espaço de desenvolvimento pessoal e profissional, contribuir para intensificar o relacionamento do Banco com a sociedade e o mercado, bem como para contribuir com a ampliação dos negócios e desenvolver o capital intelectual da organização. O resultado da aplicação dos questionários mostrou que os colaboradores concordam de maneira geral que a UC gera uma vinculação entre os indivíduos e a estratégia organizacional, adota com sucesso o modelo de gestão por competências e cria um estímulo à educação continuada. Concluiu-se que os colaboradores dessa organização percebem a UC de maneira semelhante àquela proposta pela área de Gestão de Pessoas, excetuando-se os fatores relacionados ao fato da UC provocar um aumento de visibilidade interna e externa da empresa e de promover uma relação de parceria com as tradicionais instituições de ensino. Recomenda-se para futuros estudos que haja uma amostra ampliada e mais diversificada e que seja realizada uma pesquisa qualitativa após a obtenção dos resultados pelo questionário para um aprofundamento das razões de não percepção das ações de uma UC.

1. Conhecimento Organizacional 2. Universidade Corporativa 3. Percepção de mudança 


\section{SUMÁRIO}

1. INTRODUÇÃO

1.1. Contextualização do Assunto e Apresentação do tema ...............................13

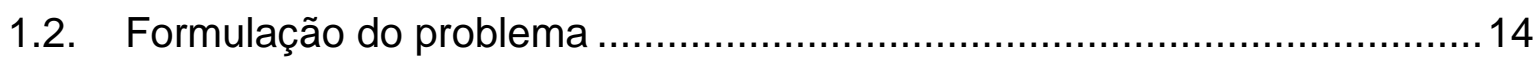

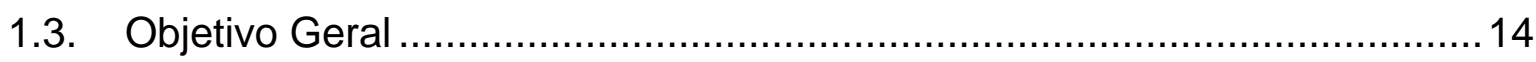

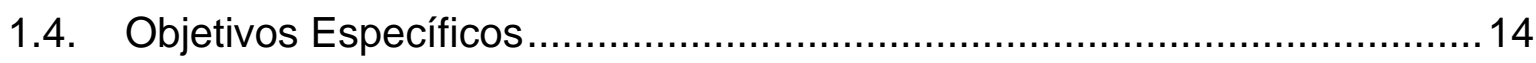

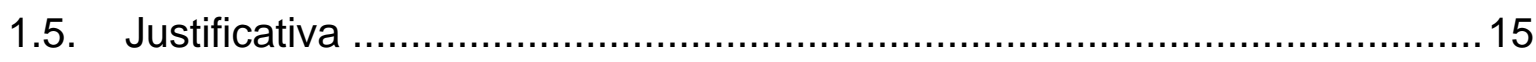

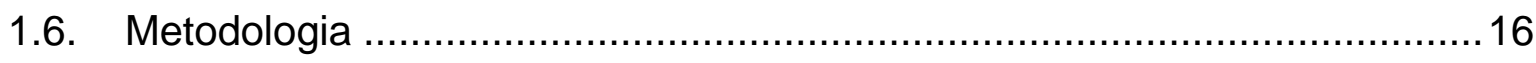

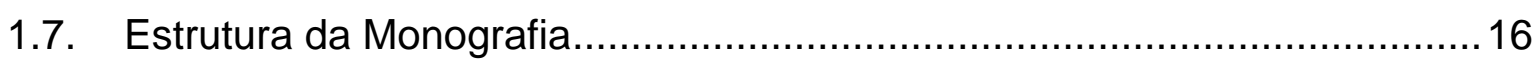

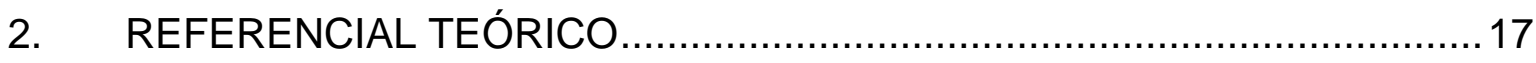

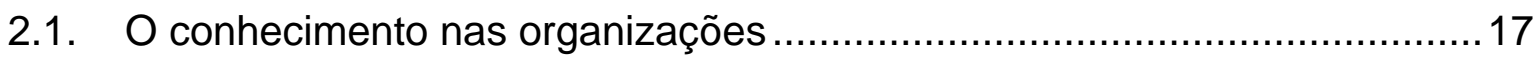

2.2. T \& D, Educação Corporativa e Universidade Corporativa .........................18

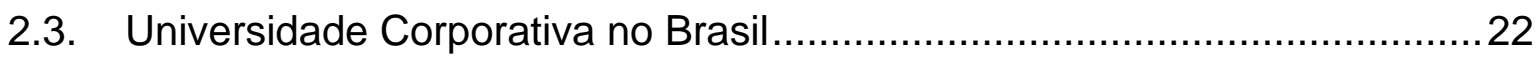

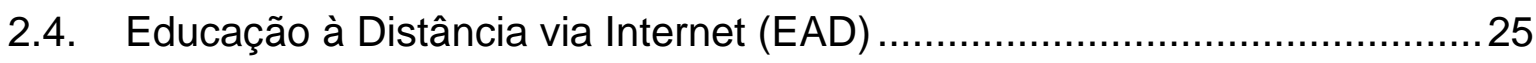

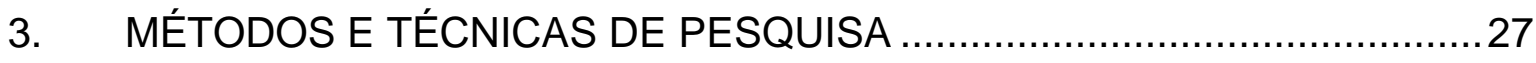

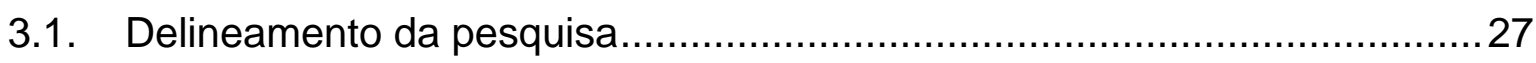

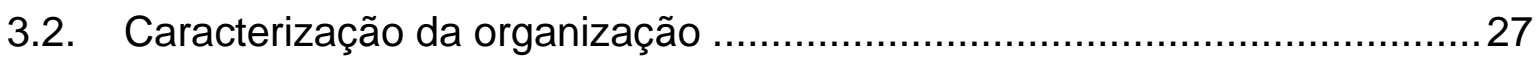

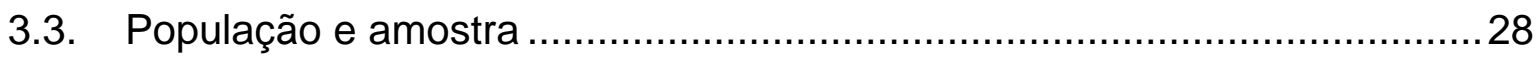

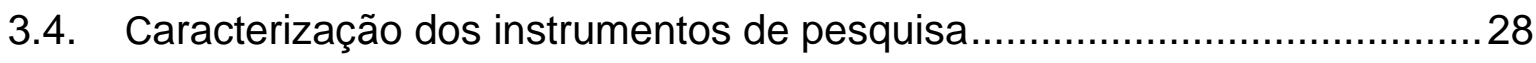

3.5. Procedimentos de coleta e análise de dados.......................................... 30

4. APRESENTAÇÃO E ANÁLISE DOS RESULTADOS DA PESQUISA .........31

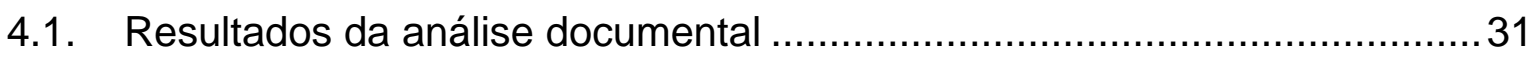

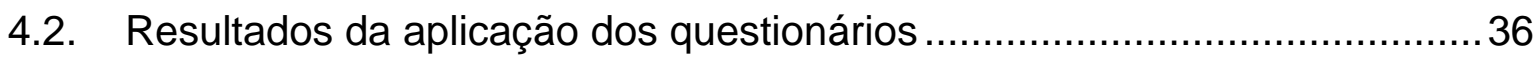

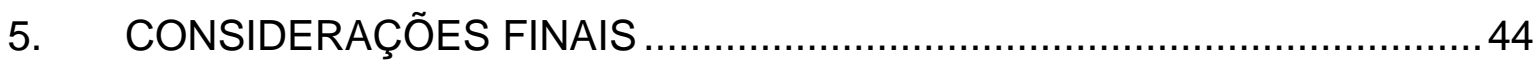

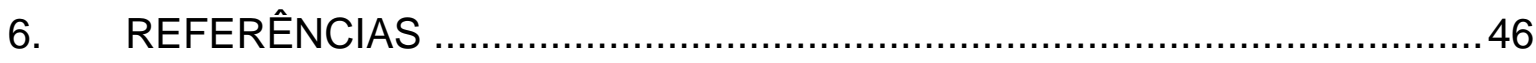

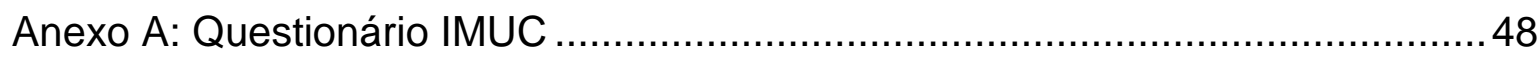




\section{LISTA DE QUADROS}

Quadro 1 - Conceitos de Universidade Corporativa .................................................. 16

Quadro 2 - Autores brasileiros e suas abordagens sobre universidade corporativa ........... 21 


\section{LISTA DE GRÁFICOS}

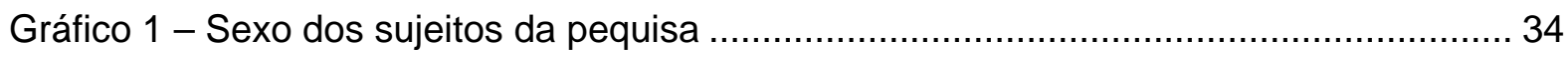

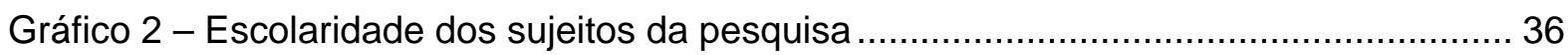

Gráfico 3 - Tipo de cargo/função dos sujeitos da pesquisa ......................................... 36 


\section{LISTA DE TABELAS}

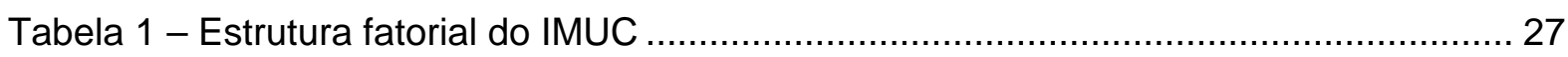

Tabela 2 - Bolsas de Graduação oferecidas pela UC .................................................. 33

Tabela 3 - Participantes do programa de aprimoramento .............................................. 33

Tabela 4 - Carga horária de treinamento oferecido pela UC …...................................... 34

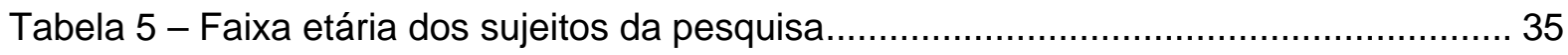

Tabela 6 - Tempo de serviço na organização dos sujeitos da pesquisa .............................. 37

Tabela 7 - Média e Desvio-Padrão dos Fatores do IMUC .............................................. 37 


\section{INTRODUÇÃO}

\subsection{Contextualização do Assunto e Apresentação do tema}

As organizações estão inseridas em um ambiente cada vez mais competitivo e dinâmico. Um exemplo disso são as constantes aquisições e fusões existentes nos mercados automobilístico, alimentício e financeiro. Exige-se, então, que as empresas possuam colaboradores qualificados que possam oferecer respostas rápidas às demandas do mercado.

Dessa forma, tornam-se necessárias ações educacionais que propiciem condições para um melhor exercício de atividades cotidianas, a partir do desenvolvimento de habilidades e atitudes necessárias à organização e uma qualificação por meio de cursos de graduação e pós-graduação.

Nesse trabalho, considera-se que a implementação de gestão do conhecimento pode ser responsável por grandes mudanças positivas nos resultados das empresas. Além disso, essa pode oferecer contribuições em longo prazo, por meio do desenvolvimento do conhecimento organizacional, que acaba sendo acumulado e transformado em diferenciais competitivos que agem a favor da empresa.

Assim sendo, dentre as diversas opções de como implementar a gestão do conhecimento, identifica-se a Universidade Corporativa (UC) como uma alternativa que pode contribuir para a qualificação dos funcionários, conforme será demonstrado no decorrer do trabalho. Acredita-se também, que os resultados podem ser maximizados quando existe uma elevada adesão por parte da cúpula da organização no que diz respeito aos temas aprendizagem organizacional, gestão do conhecimento e, mais especificamente, Universidade Corporativa.

Dessa forma, o presente trabalho se propõe a analisar a percepção dos empregados de uma instituição financeira sobre sua Universidade Corporativa, ou seja, verificar se a visão desses em relação à UC está compatível com o que a organização propõe com a implementação dessa. 


\subsection{Formulação do problema}

A presente pesquisa volta-se para a análise da percepção dos funcionários de uma Instituição Financeira, componentes do quadro de empregados de uma agência de varejo na cidade de Brasília, no que concerne ao funcionamento de sua Universidade Corporativa. Então, o problema de pesquisa pode ser definido da seguinte forma: "Quais as distinções entre a percepção dos funcionários e o que é proposto pela organização acerca da Universidade Corporativa de uma Instituição Financeira?".

\subsection{Objetivo Geral}

Para tentar responder ao problema de pesquisa supracitado estabelece-se que o objetivo geral é de avaliar, por meio da percepção dos funcionários do Banco, o funcionamento de sua Universidade Corporativa. Assim, será possível investigar se há alguma relação entre a percepção dos colaboradores e o que é proposto pela área estratégica da Gestão de Pessoas da Instituição Financeira.

\subsection{Objetivos Específicos}

- Caracterizar a Universidade Corporativa da Instituição em questão;

- Avaliar a visão da organização estudada, no que se refere aos propósitos da Universidade Corporativa;

- Analisar a visão que os funcionários do Banco têm sobre sua Universidade Corporativa;

- Discutir as possíveis diferenças existentes entre o projeto de Universidade Corporativa feito pela área de Gestão de Pessoas e o que ocorre na prática;

- Analisar as possíveis relações entre as percepções dos colaboradores e as variáveis demográficas. 


\subsection{Justificativa}

Desde a abertura do mercado brasileiro no início dos anos 1990 até os dias de hoje, o país mostra ser carente de mão-de-obra qualificada que apóie o desenvolvimento de produtos e serviços que possam competir em igualdade com os similares dos países desenvolvidos, tendo em vista que o Brasil apresenta baixos níveis educacionais. Esse fato pode ser ilustrado por meio do estudo disponível no site do IBGE (2007), que mostra que a taxa de analfabetismo brasileira para pessoas com idade acima de quinze anos é de $10 \%$.

As Universidades Corporativas começaram a aparecer nesse contexto, em apoio aos novos paradigmas vigentes de gestão do conhecimento. Seu principal papel se dá na capacitação contínua dos indivíduos para que estes desenvolvam habilidades e se tornem mais produtivos, propiciando melhores resultados às organizações. Desta forma, observa-se a importância das Universidades Corporativas, que qualificam seus profissionais com uma visão diferenciada das tradicionais universidades, com o foco educacional voltado para a sua própria área de atuação. Isso pode ser demonstrado por Tarapanoff (2004), que diz que a maior arma para a sobrevivência das organizações no novo mercado competitivo que exige constante inovação é a sua capacidade de aprendizagem e, sobretudo, de criar novos conhecimentos. Esse autor também defende que, em longo prazo, a única fonte permanente de vantagem competitiva da organização é a capacidade de aprender mais depressa do que os concorrentes. Meister (1999) aponta ainda a proliferação das Universidades Corporativas como conseqüência do crescente interesse das organizações pelo desenvolvimento permanente de empregados por meio de capacitação.

Visto isso, pode-se inferir a importância do assunto atualmente. Conforme pretende-se demonstrar neste estudo, a comparação entre o projeto teórico da cúpula da organização e o efetivo trabalho prático junto aos empregados distinguese dos demais trabalhos produzidos, tendo em vista que muitos desses focam a discussão conceitual do assunto.

Tendo por base o que foi incitado pela empresa como sendo a realidade dos pressupostos sobre a Universidade Corporativa, e uma vez extraídos os dados quanto ao aproveitamento da UC, do ponto de vista dos funcionários, se chegará ao objetivo geral deste estudo. 


\subsection{Metodologia}

A metodologia da presente monografia possui uma abordagem mista, que inclui uma etapa qualitativa e outra quantitativa. A primeira se dá pela análise documental e a segunda pela aplicação de questionários. Trata-se de uma pesquisa descritiva, ou seja, há a preocupação com a descrição dos fenômenos estudados.

\subsection{Estrutura da Monografia}

Quanto à estrutura, após essa introdução, o trabalho está dividido da seguinte forma: na próxima sessão busca relatar o referencial teórico que inclui uma análise sobre o conhecimento nas organizações, Treinamento e Desenvolvimento (T\&D), Educação Corporativa e Universidade Corporativa, UCs no Brasil além de informações sobre Educação a Distância via Internet (EAD). Depois é apresentado o plano de metodologia detalhado do estudo que engloba o tipo de pesquisa realizada, população e amostra estudada, instrumento, procedimento de coleta e análise das informações. Por fim, apresentam-se os resultados da pesquisa, as considerações finais e as referências das obras citadas nessa monografia. 


\section{REFERENCIAL TEÓRICO}

\subsection{O conhecimento nas organizações}

Segundo Raposo (2006, p. 22) "a aprendizagem é um tema que permeia os campos da educação e da gestão e tem ocupado a pauta das empresas e das universidades, saindo de uma condição periférica e mudando o modo como os negócios vêem-se a si mesmos."

Nos últimos anos, segundo Dengo (2001), as empresas preocupadas em permanecer no mercado e evoluir em seus negócios reposicionaram suas estratégias tendo em vista a valorização do conhecimento. Esse autor acredita que por meio da educação corporativa, de parcerias e consultorias no campo da educação, as empresas tentam criar expertise que lhes proporcionem vantagem competitiva.

De acordo com Vitelli (2000), a educação se constitui em vantagem competitiva quando a sistematização do conhecimento e a aprendizagem contínua forem valores fundamentais para a organização.

A percepção da importância desse tema foi diagnosticada por Senge (1998), quando preconizou uma nova formatação de estrutura organizacional denominada "Organizações de Aprendizagem". Nesse trabalho foi indicado que a tradicional área de Treinamento e Desenvolvimento (T\&D) deve-se se alinhar, cada vez mais, à estratégia organizacional na busca por melhores resultados.

Vieira e Garcia (2004) verificaram que devido à rapidez com que novas tecnologias de informação são introduzidas e renovadas, as empresas necessitam de trabalhadores polivalentes e flexíveis. Logo, nesse contexto, a gerência da organização cumpre os objetivos de desenvolver conhecimentos especialmente vinculados aos negócios da empresa e criar a cultura da aprendizagem constante, que age contra a obsolescência.

Dada a relevância do tema, verifica-se que a atitude das empresas em buscar modelos de educação exclusivos para o seu próprio meio de atuação não é um acontecimento novo, sua origem passou a ser contada a partir do século XIX (MALVEZZI, 1999; MEISTER, 1999; PONTUAL, 1980).

A difusão do conhecimento facilita a sintonia entre os objetivos individuais e os objetivos organizacionais. Para que isso ocorra, atualmente são utilizados pelas 
organizações programas de tradicionais de T\&D, ferramentas tecnológicas, como intranet, internet e educação a distância (EAD), além da Universidade Corporativa.

\title{
2.2 T\&D, Educação Corporativa e Universidade Corporativa
}

Toledo (1996, p. 83) entende que o departamento de T\&D é um subsistema da área de Recursos Humanos e que pode ser definido como:

\begin{abstract}
Processo de educação permanente no e para o trabalho que através de um conjunto de ações com objetivos definidos e metodologia efetiva responde a necessidades de conhecimentos, habilidades e atitudes, provocando mudanças, sendo transferido para o cotidiano, possibilitando novas aprendizagens e promovendo o autodesenvolvimento de indivíduos, grupos e instituições.
\end{abstract}

Meister (1999) observa quando se é dado foco para aprendizagem organizacional, e são destinados recursos suficientes para esse fim, o departamento de T\&D tende a evoluir para implantação de uma Universidade Corporativa (UC). Indaga que a postura de atuação do primeiro é reativa enquanto a da segunda é próativa. Quanto ao alcance, o departamento se restringe ao nível tático e a UC tem abrangência estratégica. E finaliza a diferenciação entre ambas no que diz respeito ao resultado: o departamento de T\&D atua como função administrativa e gera um aumento das qualificações profissionais e a UC opera como Unidade de negócios e aumenta o desempenho no trabalho.

Continuando a diferenciação entre essas duas formas de se difundir o conhecimento na organização, Alperstedt (2001) analisa que a UC difere do tradicional departamento de T\&D por aquela possuir: foco na formação estratégica de desenvolvimento de competências essenciais ao negócio, a extensão do serviço ao público externo e parcerias com instituições de ensino superior.

Para Éboli (2004), o surgimento do modelo de universidade corporativa foi o grande marco que fez a passagem da área tradicional de T\&D para uma preocupação com a educação de todos os funcionários, e não apenas de clientelas estratégicas da organização. Para a autora, o surgimento das universidades corporativas faz emergir uma modalidade de educação corporativa.

Vargas e Abbad (2006) esclarecem que, apesar dos conceitos de Educação Corporativa e Universidade Corporativa terem sido inseridos concomitantemente no ambiente organizacional, a expressão "universidade corporativa" é muito restritiva, 
porque nem toda organização precisa ou vai criar esse tipo de unidade educacional em sua estrutura.

Diante dessa assertiva, entende-se que Educação Corporativa pode ser considerada um conceito genérico que abrange as diversas maneiras pelas quais se cria, transmite e se mantém o conhecimento. Enquanto que T\&D e UC são maneiras distintas de se implantar a Educação Corporativa.

Silva (2006) propôs um quadro com os principais conceitos de Universidade Corporativa, ao mesmo tempo em que afirmou que a maioria das concepções acerca do tema converge para um ponto comum que é o estabelecimento de uma nova prática educacional que faz com que se forme um elo muito forte entre a prática e a teoria.

\begin{tabular}{|l|l|}
\hline Definição encontrada & Referência \\
\hline $\begin{array}{l}\text { Uma entidade educacional que funciona como uma ferramenta } \\
\text { estratégica desenhada para ajudar a organização-mãe a atingir } \\
\text { sua missão, por intermédio da condução de atividades que } \\
\text { cultivem a sabedoria, o conhecimento e aprendizagem individual } \\
\text { e organizacional. }\end{array}$ & \\
\hline $\begin{array}{l}\text { Uma organização central que serve a múltiplos departamentos } \\
\text { cujo objeto é ajudar a organização desenvolver nos empregados }\end{array}$ & Moore(2002) \\
as capacidades que Ihes são exigidas para o sucesso. & \\
\hline $\begin{array}{l}\text { Uma empresa cuja responsabilidade é operar como uma unidade } \\
\text { de negócio que desenvolve idéias orientadas para o negócio, } \\
\text { vinculadas às questões estratégicas da empresa. }\end{array}$ & Teixeira(2001) \\
\hline $\begin{array}{l}\text { Um conjunto de ações que visam desenvolver conhecimentos, } \\
\text { habilidades e competências alinhadas ao interesse estratégico } \\
\text { da organização e, por conseguinte, capazes de incrementar o } \\
\text { potencial competitivo da mesma. }\end{array}$ & Martins(2005) \\
\hline
\end{tabular}

Quadro 1 - Conceitos de Universidade Corporativa.

Fonte: Silva (2006, p. 23)

Analisando as definições de Universidade Corporativa percebem-se idéias centrais a respeito desse conceito, tais como: missão e aprendizagem (ALLEN, 
2002), capacitação e sucesso organizacional (MOORE, 2002) e estratégia organizacional (TEIXEIRA, 2001; MARTINS 2005).

De acordo com Éboli (2004), as primeiras Universidades surgiram nos Estados Unidos e foram criadas para complementar a formação acadêmica de seus profissionais, uma vez que as escolas tradicionais não acompanhavam o ritmo das mudanças impostas pela globalização. Ainda segundo ela, em pouco tempo houve uma enorme difusão dessa novidade pelas grandes empresas norte-americanas.

O crescimento no número de UC's também é citado por Vergara (2002), que afirma que em 1985 havia cerca 400 unidades somente nos Estados Unidos e que em 1999 esse número já passava de 2000. Dentre elas, encontram-se empresas como Disney, McDonald's, General Motors, Motorola e General Eletric.

Meister (1999, p. 29) conceitua Universidade Corporativa como "um guardachuva estratégico para desenvolver e educar funcionários, clientes, fornecedores e comunidade, a fim de cumprir as estratégias empresariais da organização". Ela acrescenta ainda que "a metáfora da universidade pode ser entendida facilmente e até imprime ao treinamento corporativo uma marca característica e que atrai a atenção dos funcionários".

De maneira semelhante Eboli (1999, p. 112) prega que a Universidade Corporativa:

\footnotetext{
Deve ser encarada como um estratégico guarda-chuva para todo tipo de educação, para todos os empregados e também consumidores, fornecedores e comunidade. Ela é sobretudo um processo e uma mentalidade que permeia toda a organização, e não apenas um local físico de aprendizado. A missão da Universidade corporativa consiste em formar e desenvolver os talentos humanos na gestão dos negócios, promovendo a gestão do conhecimento organizacional (geração, assimilação, difusão e aplicação), por meio de um processo de aprendizagem ativa e contínua.
}

Observa-se Éboli (1999) mostra que a UC engloba os principais stakeholders, ou seja, não se restringe apenas aos colaboradores internos da organização.

Meister (1999) defende ainda que as Universidades Corporativas sejam as dependências internas de educação e treinamento que surgiram nas empresas por causa da frustração com a qualidade e o conteúdo da educação pós-secundária e da necessidade de um aprendizado permanente.

Segundo Meister (1999), o ensino a distância nas UC's em particular o elearning, está assumindo importante papel, pois oferece ao indivíduo a possibilidade 
de estudar a qualquer hora e em qualquer lugar, acelerando seu aprendizado. Aponta ainda os recursos multimídia como contribuição significativa para que as universidades corporativas configurem-se como inovadores laboratórios de aprendizagem, nos quais diferentes maneiras de disseminar o conhecimento são implementadas.

A expansão das Universidades Corporativas e sua utilização como estratégia de desenvolvimento de profissionais torna importante o conhecimento de seus princípios e funcionamento. Trata-se de uma universidade que oferece cursos técnicos e gerenciais específicos para os colaboradores da corporação. Assim, ela customiza os cursos exatamente de acordo com as políticas e estratégias das empresas, reduz custos do treinamento convencional e obtém rapidez na formação da mão de obra. Em outras palavras, são programas de capacitação orientados para os objetivos da organização, de caráter intensivo e permanente (BRANDÃO, 2006).

A Universidade Corporativa, segundo Eboli (1999), é também um resgate da clássica integração entre escola e empresa. Seus objetivos de aprendizagem estão sintonizados aos interesses, objetivos e estratégias das empresas que promovem a formação dos seus funcionários..

A universidade corporativa está muito ligada à gestão do conhecimento, uma vez que a primeira busca promover a segunda por meio da formação e desenvolvimento de talentos na gestão dos negócios. O objetivo principal de uma universidade corporativa é o desenvolvimento e a instalação das competências profissionais, técnicas e gerenciais consideradas essenciais para a viabilização das estratégias negociais (EBOLI, 1999). A implantação de uma universidade corporativa busca ainda a difusão do princípio de que o capital intelectual é o grande diferencial das empresas do futuro, despertar a vocação pelo aprendizado nas pessoas e incentivar o auto-desenvolvimento.

Para essa efetiva implantação, Eboli (1999) lista alguns pressupostos, tais como: o desenvolvimento de competências críticas, foco no aprendizado organizacional, atender ao público interno e externo e a concentração nas necessidades do negócio, tomando o escopo estratégico. Estes passos devem estar em consonância para que as universidades corporativas não sejam apenas meros centros de T\&D remodelados. Também é de grande importância o estabelecimento de parcerias com instituições de ensino tradicionais. Estas instituições de ensino tradicionais possuem grande experiência em pesquisa e educação. Desta forma, 
uma parceria torna possível promover, com mais eficácia, a gestão do conhecimento. As empresas, em vez de entregarem uma lista de necessidades ao ensino superior, estão especificando as habilidades, o conhecimento e as competências necessárias. Nesse processo, estão criando programas conjuntos de educação formalmente reconhecidos (MEISTER, 1999).

No entanto, tudo o que foi exposto não é uma fórmula exata para que as empresas se tornem mais eficazes na capacitação e treinamento de seus colaboradores, no sentido de atingir os objetivos individuais e coletivos. São necessárias também pesquisas básicas e aplicadas, de forma a tornar mais possível o alcance dos objetivos de criação e transmissão de conhecimento dentro da organização.

As universidades corporativas devem estar integradas e alinhadas às estratégias e aos processos que compõem a área de gestão de pessoas (BRANDÃO, 2006). A universidade corporativa representa um leque de características na busca da competitividade, no entanto esse caráter extremamente abrangente deve ser motivo para aumentar a clareza e discernimento quanto aos objetivos, concepções e valores com as quais as empresas desejam atuar.

\subsection{Universidades Corporativas no Brasil}

Raposo (2006) afirma que este é um fenômeno que ganhou impulso no Brasil na década de 1990, e que hoje registra inúmeras experiências tanto na iniciativa privada quanto em organizações do governo. E adiciona que o Ministério do Desenvolvimento, Indústria e do Comércio Exterior (MDIC) vem estimulando o desenvolvimento das UCs, mediante a promoção de eventos e debates entre empresas que já possuem unidades instaladas e outras que pretendem implementálas. Um exemplo desse apoio do Ministério se coaduna com a criação, em 2004, da Associação Brasileira de Educação Corporativa (ABEC), que congrega boa parte das UC's existentes no País.

Segundo Eboli (2004), no Brasil as UCs são denominadas como setoriais, ou seja voltada para setores produtivos ou categorias profissionais específicas, mais especificamente do ramo das Instituições Financeiras e do ramo alimentício. Alertando que não possui a mesma diversidade de aplicação como observada, por exemplo, nos Estados Unidos. 
As experiências pioneiras de Universidade Corporativa no Brasil são as das empresas Accor Brasil, Algar, Amil, Brahma, BankBoston, Elma Chips, Ford, Mac Donalds, Banco do Brasil e Motorola (CARVALHO, 2001).

No estudo de Alperstedt, em 2001, essa constatou que existem cerca de 52 universidades corporativas no país, sendo que a grande maioria, ou seja, 36 delas, está no estado de São Paulo. Destas, 54,5\% estão no setor de serviços; 36,4\% são ligadas à área do conhecimento; 9,1\% no setor de bens de consumo.

Apesar de ter ocorrido um crescimento de estudos e de implantações de unidades no final da década de 1990 no Brasil, Raposo (2006) afirma que o tema carece de estudos acadêmicos que Ihes dêem sustentação.

Vargas (2006, p. 379) aponta os desafios que enfrentam as universidades corporativas, em um contexto de não consolidação de seu campo organizacional:

\begin{abstract}
Uma universidade corporativa propõe-se resolver, entre outros, este desafio: o de ligar a função treinamento aos objetivos e estratégias organizacionais. Muitas organizações estão vivenciando um processo de migração para um novo modelo de treinamento e desenvolvimento de pessoal mais adequado à nova era do conhecimento, apoiando-se no uso das universidades corporativas ou de outras alternativas,para organização e difusão da informação e da aprendizagem. Por tratar-se de um momento recente na história das organizações existem poucos estudos e pesquisas relatando a dinâmica dessa transformação. No caso particular das Universidades Corporativas, uma dessas alternativas de T\&D, ainda existem lacunas sobre o que elas realmente representam, para que servem e, principalmente, qual a melhor maneira de estruturá-las de modo que possam agregar valor à organização.
\end{abstract}

Já Brandão (2006), ao realizar um estudo de caso acerca da Universidade Corporativa de uma instituição financeira relacionou os principais artigos e pesquisas dos autores brasileiros sobre o tema, conforme se observa no Quadro 2.

\begin{tabular}{|c|c|c|c|}
\hline Autor/ano & Objetivo & Metodologia & Resultados Encontrados \\
\hline $\begin{array}{l}\text { Alperstedt } \\
(2000)\end{array}$ & $\begin{array}{lr}\text { Propor definição para } \\
\text { as UCs, a partir de } \\
\text { critérios } & \text { de } \\
\text { diferenciação } & \text { dos } \\
\text { T\&Ds. } & \end{array}$ & $\begin{array}{l}\text { Artigo teórico- } \\
\text { conceitual: pesquisa } \\
\text { bibliográfica. }\end{array}$ & $\begin{array}{l}\text { Definição propõe } \\
\text { características } \\
\text { concomitantes: } \\
\text { - desenvolvimento de } \\
\text { competências essenciais ao } \\
\text { negócio; } \\
\text {-extensão dos serviços à } \\
\text { cadeia de valor; } \\
\text { - parcerias com instituições } \\
\text { de ensino superior. }\end{array}$ \\
\hline
\end{tabular}




\begin{tabular}{|c|c|c|c|}
\hline $\begin{array}{l}\text { Alperstedt } \\
\text { (2001) }\end{array}$ & $\begin{array}{l}\text { Identificar a } \\
\text { representação das UCs } \\
\text { para as instituições de } \\
\text { ensino superior: } \\
\text { concorrência potencial } \\
\text { ou oportunidades } \\
\text { estratégicas? }\end{array}$ & $\begin{array}{l}\text { Pesquisa qualitativa } \\
\text { exploratória; estudo } \\
\text { de casos: } 4 \text { UCs } \\
\text { brasileiras e } 3 \text { UCs } \\
\text { americanas }\end{array}$ & $\begin{array}{l}\text { As UCS são representativas } \\
\text { de concorrência para áreas } \\
\text { como: administração, } \\
\text { engenharia e ciências da } \\
\text { informação, especialmente } \\
\text { em cursos de pós-graduação } \\
\text { e outros segmentos de } \\
\text { público adulto. }\end{array}$ \\
\hline $\begin{array}{l}\text { Amaral } \\
(2003)\end{array}$ & $\begin{array}{l}\text { Construir um quadro de } \\
\text { referência teórico- } \\
\text { prático sobre EC, para } \\
\text { fins de instrumento de } \\
\text { avaliação. Identificar } \\
\text { políticas e práticas que } \\
\text { representem a a } \\
\text { valorização da EC em } \\
\text { suas múltiplas } \\
\text { dimensões. }\end{array}$ & $\begin{array}{l}\text { Pesquisa qualitativa } \\
\text { exploratória; estudo } \\
\text { de caso }\end{array}$ & $\begin{array}{l}\text { Referências teórico-práticas e } \\
\text { proposta de EC em seis } \\
\text { dimensões. Em termos de } \\
\text { práticas e políticas, a visão } \\
\text { sobre educação corporativa é } \\
\text { simplificada e parcial; o } \\
\text { processo de gestão, } \\
\text { fragmentado, com visão } \\
\text { estratégica e de totalidade } \\
\text { em construção }\end{array}$ \\
\hline $\begin{array}{c}\text { Camargo } \\
(2001)\end{array}$ & $\begin{array}{l}\text { Identificar os aspectos } \\
\text { mais significativos da } \\
\text { contribuição dos } \\
\text { programas de UC para } \\
\text { o desenvolvimento de } \\
\text { competências } \\
\text { individuais dos } \\
\text { gestores. }\end{array}$ & $\begin{array}{l}\text { Pesquisa qualitativa } \\
\text { descritiva; estudo de } \\
\text { caso }\end{array}$ & \begin{tabular}{lrr} 
Identificou & \multicolumn{2}{c}{ contribuições } \\
significativas & da & UC; \\
construiu modelo & de \\
prestação de serviços & no \\
setor; identificou & as \\
competências individuais \\
necessárias. A UC & como \\
veículo positivo & de \\
desenvolvimento & de \\
competências gerenciais.
\end{tabular} \\
\hline $\begin{array}{l}\text { Dengo } \\
(2001)\end{array}$ & $\begin{array}{l}\text { Identificar as bases } \\
\text { teórico-empíricas que } \\
\text { sustentam o modelo de } \\
\text { UC, verificando seu } \\
\text { alinhamento com o } \\
\text { conceito proposto por } \\
\text { Meister (1999). }\end{array}$ & $\begin{array}{l}\text { Pesquisa qualitativa } \\
\text { exploratória; estudo } \\
\text { de caso }\end{array}$ & $\begin{array}{l}\text { As Ucs nos moldes dos } \\
\text { centros de T\&D; distantes } \\
\text { dos conceitos de Meister } \\
\text { (1999); configurando-se } \\
\text { como modismo e não como } \\
\text { inovação }\end{array}$ \\
\hline $\begin{array}{l}\text { Eboli } \\
(1999 ; \\
2002)\end{array}$ & $\begin{array}{l}\text { Estudar as } \\
\text { experiências de UC no } \\
\text { Brasil, construindo } \\
\text { análise ampla sobre o } \\
\text { tema e suas interfaces } \\
\text { com o ensino superior. }\end{array}$ & $\begin{array}{l}\text { Pesquisa } \\
\text { bibliográfica e de } \\
\text { campo. }\end{array}$ & $\begin{array}{l}\text { Pesquisa em andamento. } \\
\text { Produções: } \\
\text { - coletânea sobre UC no } \\
\text { Brasil; } \\
\text { - identificação de UCs no } \\
\text { Brasil: quais e quantas; } \\
\text { - orientações para conceber e } \\
\text { implantar sistemas } \\
\text { educacionais; } \\
\text { - análise da UC incluindo } \\
\text { interface com instituições de } \\
\text { ensino superior e com gestão } \\
\text { do conhecimento; } \\
\text { - artigos em revistas, livros, } \\
\text { periódicos }\end{array}$ \\
\hline
\end{tabular}




\begin{tabular}{|c|c|c|c|}
\hline $\begin{array}{l}\text { Knijnik } \\
(2001)\end{array}$ & $\begin{array}{c}\text { Comparar o modelo de } \\
\text { T\&D do Grupo Gerdau } \\
\text { e o modelo da Unialgar } \\
\text { - Grupo Algar. }\end{array}$ & $\begin{array}{c}\text { Pesquisa qualitativa } \\
\text { descritiva; estudo de } \\
\text { caso }\end{array}$ & $\begin{array}{l}\text { Tendência de a unidade de } \\
\text { T \& D do Grupo Gerdau } \\
\text { evoluir para modelo de UC. }\end{array}$ \\
\hline $\begin{array}{l}\text { Marcondes } \\
\text { \& Paiva } \\
\text { (2001) }\end{array}$ & $\begin{array}{c}\text { Identificar a diferença } \\
\text { de concepção e } \\
\text { atuação entre UC e } \\
\text { T\&D. }\end{array}$ & $\begin{array}{c}\text { Pesquisa qualitativa } \\
\text { exploratória; estudo } \\
\text { de caso. }\end{array}$ & $\begin{array}{c}\text { Preocupação com } \\
\text { desenvolvimento de } \\
\text { competências individuais e } \\
\text { gerenciais; maior } \\
\text { alinhamento às estratégias } \\
\text { corporativas são os principais } \\
\text { pontos inovadores em } \\
\text { relação ao T\&D. Outros } \\
\text { impasses são mantidos. }\end{array}$ \\
\hline $\begin{array}{c}\text { Nasser } \\
\text { (2001) }\end{array}$ & $\begin{array}{l}\text { A partir da ótica da UC, } \\
\text { busca informação e } \\
\text { discute a metodologia } \\
\text { adotada pela UC e o } \\
\text { papel da informação } \\
\text { nesse processo. }\end{array}$ & $\begin{array}{c}\text { Pesquisa qualitativa } \\
\text { descritiva; estudo de } \\
\text { caso. }\end{array}$ & $\begin{array}{l}\text { Relevância do papel da } \\
\text { informação nas UCs. } \\
\text { Identifica práticas } \\
\text { educacionais em que a } \\
\text { informação e o conhecimento } \\
\text { são considerados fatores } \\
\text { competitivos. Releva o } \\
\text { conceito de aprendizagem } \\
\text { sob demanda e suas práticas } \\
\text { alinhadas ao mapa de } \\
\text { competências das empresas } \\
\text { estudas. }\end{array}$ \\
\hline $\begin{array}{c}\text { Vitelli } \\
(2000)\end{array}$ & $\begin{array}{l}\text { Questionar a UC como } \\
\text { fonte de vantagem } \\
\text { competitiva e de } \\
\text { criação de ambiente de } \\
\text { aprendizagem. }\end{array}$ & $\begin{array}{l}\text { Artigo teórico- } \\
\text { conceitual: pesquisa } \\
\text { bibliográfica }\end{array}$ & $\begin{array}{l}\text { As conclusões evidenciam } \\
\text { que as UCs, per se, não } \\
\text { garantem vantagem } \\
\text { competitiva sustentável às } \\
\text { organizações, se estas não } \\
\text { priorizarem ações ligadas à } \\
\text { gestão do conhecimento e à } \\
\text { cultura de aprendizagem. }\end{array}$ \\
\hline
\end{tabular}

Quadro 2 - Autores brasileiros e suas abordagens sobre universidade corporativa. Fonte: Brandão (2006 p. 25)

Ao se analisar o Quadro 2, pode-se notar que existe uma forte predominância de metodologia constituídas por pesquisas qualitativas e de objetivos em sua maioria voltados para a discussão de conceitos e definições sobre o tema.

\subsection{Educação à Distância via Internet (EAD)}

Segundo Meister (1999), a velocidade com que surgem novos produtos e serviços e a diminuição dos ciclos de produção e de vida desses fazem com que as 
informações e treinamentos disseminados na organização tornem-se rapidamente obsoletos. Dessa forma, a autora sugere que para que a Educação organizacional seja eficiente é necessária uma evolução na dinâmica de transmissão de conhecimentos. É nesse contexto que surge a Educação a Distância via Internet (EAD).

De acordo com Ghedine e Freitas (2003), o crescimento da utilização desse método de ensino vem aumentando devido aos altos custos da educação presencial, e de suas limitações de ordem temporal e geográficas para os alunos, a importância crescente da aprendizagem continuada e a evolução constante das tecnologias interativas de comunicação.

Esse acrescenta que com o advento da rede mundial de computadores, a Internet, vários benefícios estão sendo agregados para a educação organizacional, como por exemplo, a conectividade e alcance global, interatividade, flexibilidade e personalização e distribuição acelerada do conhecimento.

Moore e Kearsley (1996, apud GHEDINE; FREITAS, 2003 p.4) apresentam uma definição para EAD:

Educação a distância é a aprendizagem planejada que geralmente ocorre num local diferente do ensino e, por causa disso, requer técnicas especiais de desenho de curso, técnicas especiais de instrução, métodos especiais de comunicação e através da eletrônica e outras tecnologias, bem como arranjos essenciais organizacionais e administrativos.

Já Urdan e Weggen (2000, apud GHEDINE; FREITAS, 2003 p.4) definem EAD de uma forma mais abrangente e exemplificativa:

\begin{abstract}
Situação educacional na qual o instrutor e o estudante estão separados pelo tempo, localização geográfica, ou ambos. A educação ou o curso de treinamento são entregues em locais remotos via meios de comunicação síncrono ou assíncrono, incluindo correspondências escrita, textos, gráficos, áudio e vídeo tape, CD-ROM, aprendizado online, áudio e videoconferências, TV interativa e fax
\end{abstract}

Segundo Ghedine e Freitas (2003) existe uma falta de senso comum sobre o assunto tanto na academia quanto no mercado, porém a principal idéia na definição desse objeto de estudo é o fato de aluno e professor estar separado fisicamente e, na maioria das vezes, também, temporalmente 


\section{MÉTODOS E TÉCNICAS DE PESQUISA}

\subsection{Delineamento da pesquisa}

Tendo em vista os objetivos do presente estudo, a escolha pelo tipo de pesquisa foi pela abordagem mista, pois há uma etapa qualitativa, que inclui a análise documental para verificar o que a alta administração busca com a UC, e outra quantitativa com a aplicação de questionários junto aos empregados da Instituição.

De acordo com a classificação estabelecida por Vergara (2000), a monografia em questão é considerada quanto aos fins como pesquisa descritiva, pois o mesmo se preocupa com a descrição do fenômeno estudado sem se preocupar com a explicação dos fatores envolvidos. Já quanto aos meios, pode-se considerar como bibliográfica, documental e pesquisa de campo. A primeira por conter uma revisão da literatura sobre os conceitos envolvidos ao tema, a segunda por haver análise de informações contidas em materiais fornecidos pela UC e no do site da Instituição e a terceira advém da investigação por meio de questionários aplicados junto aos funcionários da organização pesquisada.

\subsection{Caracterização da organização}

A pesquisa foi realizada em uma instituição financeira do setor de serviços. Trata-se de uma sociedade de economia mista com sede em Brasília-DF e com atuação em todas as regiões do país. Essa organização foi escolhida por ser uma das pioneiras na implantação da Universidade Corporativa no Brasil e por essa possuir tradição e reputação na área de T\&D (BRANDÃO, 2006).

Ressalta-se que não foi possível haver uma caracterização mais detalhada, pois a organização não pôde ser identificada. 


\subsection{População e Amostra}

A amostra documental é representada por todo material disponibilizado no site da instituição financeira sobre sua Universidade Corporativa e pelos materiais fornecidos pela UC de cursos definidos como obrigatórios pela organização para os funcionários de agência com até seis meses de tempo de serviço.

A unidade estudada é a maior agência bancária de Brasília em número de funcionários e em número de clientes. Então a escolha dessa agência trouxe maior representatividade à pesquisa.

A população da pesquisa é a soma de todos os funcionários da agência e perfazem um total de 61 colaboradores. Entende-se por funcionários aqueles que ingressaram na instituição por meio de concurso, ou seja, estão excluídos os estagiários, terceirizados e menores aprendizes. Logo, apenas os empregados públicos foram alvo da presente pesquisa.

A amostra foi composta de 49 funcionários, e teve representantes de todas as áreas da unidade, que incluem os setores de pessoa jurídica, atendimento de pessoa física de baixa, média e alta renda, setor de suporte, bateria de caixas, autoatendimento e administração.

\subsection{Caracterização do Instrumento de pesquisa}

A coleta dos dados foi feita por meio do uso de uma medida (Anexo A) chamada de Instrumento de Mudança Organizacional provocada pelas Universidades Corporativas (IMUC) construído e validado por Silva (2006).

Os itens do questionário representam cinco fatores, quais sejam: Vinculação das ações educacionais às estratégias da organização; Estabelecimento das parcerias entre a organização e instituições de ensino; Foco no modelo de gestão por competências; Aumento da visibilidade interna e externa da empresa e Estímulo a educação continuada, perfazendo um total de 32 itens.

Como ilustração, segue a Tabela $1 \mathrm{com}$ a estrutura fatorial do IMUC com o respectivo conceito de cada fator e os itens correspondentes. 
Tabela 1 - Estrutura fatorial do IMUC

Fonte: Silva (2006, p.57).

\begin{tabular}{|c|c|c|}
\hline FATORES & CONCEITO & ITENS \\
\hline $\begin{array}{l}\text { Vinculação } \quad \text { das ações } \\
\text { educacionais às estratégias da } \\
\text { organização }\end{array}$ & $\begin{array}{l}\text { Adoção de ações educacionais viabilizadas pela } \\
\text { UC que permitam o alinhamento com a estratégia } \\
\text { da Organização }\end{array}$ & $\begin{array}{c}17,24,6 \\
15,8\end{array}$ \\
\hline $\begin{array}{l}\text { Estabelecimento das parcerias } \\
\text { entre a organização e instituições } \\
\text { de ensino }\end{array}$ & $\begin{array}{l}\text { Surgimento de novas práticas entre organizações, } \\
\text { em decorrência do estabelecimento de parcerias } \\
\text { com o meio acadêmico, proporcionadas pela } \\
\text { implantação de uma universidade corporativa }\end{array}$ & $\begin{array}{c}31,7,19,5 \\
, 13 .\end{array}$ \\
\hline $\begin{array}{l}\text { Foco no modelo de gestão por } \\
\text { competências }\end{array}$ & $\begin{array}{l}\text { Adoção de modelo de gestão baseado em } \\
\text { competências o qual possibilita à organização } \\
\text { identificar e desenvolver as competências internas } \\
\text { e externas necessárias à manutenção e ao } \\
\text { destaque no mercado em que está inserida. }\end{array}$ & $\begin{array}{c}4,29,16,9 \\
, 18 .\end{array}$ \\
\hline $\begin{array}{l}\text { Aumento da visibilidade interna e } \\
\text { externa da empresa }\end{array}$ & $\begin{array}{l}\text { A partir da implantação de uma universidade } \\
\text { corporativa, as empresas passam a oferecer } \\
\text { treinamento e outras ações de aprendizagem às } \\
\text { empresas parceiras e às comunidades onde estão } \\
\text { localizadas. Com essa prática, aumentam a sua } \\
\text { visibilidade externa. }\end{array}$ & $\begin{array}{l}23,20,3,3 \\
2,12,21 \\
27\end{array}$ \\
\hline Estímulo a educação continuada & $\begin{array}{l}\text { Com a implantação da universidade corporativa, } \\
\text { ampliaram-se as oportunidades de aprendizagem } \\
\text { nas organizações, tanto de forma presencial quanto } \\
\text { a distância. Diferentes ações de aprendizagem são } \\
\text { viabilizadas pelo emprego de tecnologias da } \\
\text { informação que, dentre outras contribuições, } \\
\text { estimulam a criação de redes virtuais para troca de } \\
\text { conhecimento, permitindo assim, um maio diálogo, } \\
\text { debates e trocas de experiências. As informações } \\
\text { passam a ser democratizadas, os canais de } \\
\text { comunicação são ampliados e o compartilhamento } \\
\text { do conhecimento é estimulado. }\end{array}$ & $\begin{array}{c}30,11,26 \\
2,28,14 \\
22,10,25 \\
1\end{array}$ \\
\hline
\end{tabular}

As variáveis independentes analisadas nessa pesquisa propostas foram: sexo, idade, escolaridade, tempo de serviço e qual cargo ou função ocupada. 


\subsection{Procedimentos de coleta e análise dos dados}

A obtenção das informações foi realizada por meio da aplicação dos questionários, que ocorreu em dois dias, tendo em vista que grande parte do quadro de funcionários trabalha em atendimento ao público e não pode se ausentar de seus postos em horários de expediente para responderem aos questionários. No primeiro dia foi abordado metade dos funcionários de cada setor, tendo ocorrido o mesmo no segundo dia com a segunda metade dos funcionários, de modo a não prejudicar o andamento do serviço. Os questionários foram entregues pessoalmente pelo pesquisador, com o objetivo de haver um maior controle em relação aos resultados.

A técnica utilizada para a análise das informações foi realizada pelo software Statistical Package for the Social Sciences (SPSS) versão 17.0, que transformou os dados em informações relevantes para o estudo por meio de estatística descritiva, mais especificamente média e desvio padrão dos fatores que constam no instrumento.

Foram calculadas as freqüências e percentuais, assim como utilizados gráficos para descrever as características dos participantes da pesquisa. Também foram realizadas correlações de Pearson entre os fatores do IMUC e as variáveis demográficas, a fim de verificar se há relações entre essas variáveis. 


\section{APRESENTAÇÃO E ANÁLISE DOS RESULTADOS DA PESQUISA}

Neste capítulo, serão apresentados os resultados da pesquisa. Primeiramente, é descrito o resultado da pesquisa documental e, posteriormente, os resultados obtidos com a aplicação dos questionários.

\subsection{Resultados da análise documental}

A Universidade Corporativa da Instituição Financeira em questão é um subsistema da Diretoria de Gestão de Pessoas, estando a ela submetido hierarquicamente. Essa se propõe a desenvolver quatro aprendizagens essenciais para os profissionais do mercado atual:

- Aprender a Conhecer - conciliar uma cultura geral, ampla o suficiente, com a necessidade de aprofundamento em uma área específica de atuação, construindo as bases para se aprender ao longo de toda a vida;

- Aprender a Fazer - desenvolver a capacidade de enfrentar situações inusitadas que requerem, na maioria das vezes, o trabalho coletivo em pequenas equipes ou em unidades organizacionais maiores; assumir iniciativa e responsabilidade em face das situações profissionais;

- Aprender a Conviver - perceber a crescente interdependência dos seres humanos, buscando conhecer o outro, sua história, tradição e cultura e aceitando a diversidade humana. A realização de projetos comuns, a gestão inteligente e pacífica dos conflitos envolvem a análise compartilhada de riscos e a ação conjunta em face dos desafios do futuro;

- Aprender a Ser - desenvolver a autonomia e a capacidade de julgar, bem como fortalecer a responsabilidade pelo autodesenvolvimento pessoal, profissional e social.

Segundo o site da organização, os eixos metodológicos pelos quais se orientam a Universidade Corporativa da organização são:

O participante: sujeito da educação - o aprendiz é reconhecido como agente da educação; daí ser denominado "participante". É ressaltada a dimensão da cidadania, ou seja, a ação efetiva de cada indivíduo para interferir no destino da 
comunidade. As tendências pedagógicas que buscam formatar o educando como ente passivo, mero receptor de conteúdos, são rejeitadas;

A problematização da realidade: os temas estudados referem-se a questões relevantes para os participantes e são apresentados de maneira não-dogmática. Nas ações educacionais internas, os problemas concretos do Banco são levantados e analisados pelos funcionários, possibilitando o desenvolvimento da capacidade crítica, a partir de uma visão multilateral da realidade;

O método socializador e dialógico: o trabalho educacional é cooperativo, dirigido à elaboração conjunta de um saber que resulta da síntese entre teoria e prática. Além das técnicas de ensino individuais, utilizam-se técnicas socializadoras, fundamentadas no diálogo e no trabalho em equipe;

A democratização do saber: a vida no trabalho e na sociedade é parte da produção coletiva do saber; assim, o conhecimento e a oportunidade de aprender são compartilhados num espaço de igualdade;

A educação contínua: a aprendizagem é fundamentada na visão da educação como processo permanente e no propósito de autodesenvolvimento, favorecendo a humanização dos homens e mulheres que participam da ação educativa. A educação no trabalho é dinâmica e contínua e leva em consideração a atividade (tarefa), as pessoas (funcionários) e o contexto (ambiente);

A visão global e integrada da dinâmica do Banco: as ações educacionais direcionadas aos funcionários consideram o Banco em sua totalidade (unidades, funcionários, clientes, fornecedores e parceiros) e em suas relações com o País e o mundo. A interdisciplinaridade e a troca de experiências entre os funcionários concretizam a idéia da dependência entre as partes e o todo. O planejamento educacional procura adequar o processo de ensino-aprendizagem às características do Banco, inserido num contexto social em permanente transformação.

A estrutura da Universidade em questão abrange 12 unidades regionais, localizadas nas principais capitais do Brasil. São um total de 94 salas de aula, podendo atender a 2600 treinandos simultaneamente. Existem ainda 11 auditórios com capacidade total de 1100 alunos.

Os instrutores são formados por professores e técnicos contratados do mercado e principalmente por pessoas do próprio quadro de funcionários da Instituição que são treinados para o cumprimento do papel de multiplicador de conhecimento. 
O papel da UC da presente organização é de desenvolver a excelência humana e profissional de seus públicos, por meio da criação de valor em soluções educacionais, contribuindo para a melhoria do desempenho organizacional e para o fortalecimento da imagem institucional do Banco.

A instituição em todo material fornecido aos alunos, mostra o papel da UC e que a organização considera o aluno como (i) sujeito do seu processo formativo: participa da ação que gera o seu próprio crescimento e o desenvolvimento da Organização, (ii) um ser situado histórica e culturalmente, capaz de compreender e transformar sua realidade, (iii) um ser de consciência, com capacidade de apreensão e analise critica, capaz de lidar com a complexidade de seu mundo, (iv) um ser de liberdade, isto é, ele é capaz de superar os condicionamentos de sua situação, de nela intervir pessoalmente, aceitando-a, rejeitando-a ou transformando-a, (v) uma pessoa que, ao lidar com os desafios profissionais, faz a diferença, na medida em que detém conhecimentos e capacidade intelectual que conferem um caráter único à empresa, (vi) um agente de resultados, capaz de posicionar a empresa na liderança dos mercados em que atua, e (vii) um sujeito atuante no desenvolvimento das pessoas com as quais se relaciona, por meio da transmissão do conhecimento no convívio pessoal e profissional.

Verificou-se na análise do site da organização e nos materiais de divulgação oferecidos aos alunos que essa organização acredita que a Universidade Corporativa:

- Contribui para o fortalecimento da imagem do Banco;

- Desenvolve a excelência humana e profissional de seus públicos;

- Estimula a criatividade e a inovação;

- Favorece o desenvolvimento da cultura empresarial;

- Amplia as oportunidades de pesquisa;

- Cria uma base corporativa de conhecimentos que assegura a competitividade do Banco;

- Estimula a organização de espaços educativos em todas as unidades do Banco;

- Amplia a comunidade de aprendizagem do Banco;

- Expande oportunidades educacionais ligadas à profissionalização, ao desenvolvimento da cidadania, da qualidade de vida e da cultura ; 
- Democratiza o acesso ao conhecimento, por meio de recursos de educação à distância;

- Valoriza o papel de gestores e executivos, que atuam como educadores;

- Estabelece parcerias com instituições de ensino.

Observou-se ainda que a UC tem como principais objetivos institucionais: ser amplamente reconhecida pela qualidade de seus programas, ser percebida pelos funcionários como um importante espaço de desenvolvimento pessoal e profissional, contribuir para intensificar o relacionamento do Banco com a sociedade e o mercado, contribuir com a ampliação dos negócios, desenvolver o Capital Intelectual da organização.

A organização sistemática da educação corporativa da organização existe desde 1965 e foi desenhada para disponibilizar as seguintes oportunidades: (i) aprendizagem por meio de diversificadas e modernas tecnologias educacionais, dentre as quais ensino presencial, treinamento em serviço e a distância (mídia impressa, vídeo, treinamento baseado em computador e na web); (ii) programas em parceria com as melhores instituições de ensino do País; (iii) variadas opções de autodesenvolvimento, tais como biblioteca para consultas a livros e periódicos especializados, bancos de teses, dissertações e monografias; (iv) Portal Virtual, com acesso via Internet e Intranet, que permite acessar publicações digitalizadas, biblioteca virtual, sumário de periódicos, trilhas de desenvolvimento profissional, treinamento baseado em tecnologia web, dentre outros.

A organização mantém os programas de educação corporativa que podem ser agrupados em:

- Ciclos de palestras: destinados a atualização técnico- gerencial

- Cursos internos: presenciais, auto-intrucionais e em serviço

- Programa de formação e aperfeicoamento em nível superior, que inclui:

bolsas de graduação, bolsas de pós-graduação lato sensu, em nível de especialização, e bolsas de pós-graduação stricto sensu - mestrado e doutorado.

- Programa de Desenvolvimento em Idiomas Estrangeiros;

- Programa MBA - Desenvolvimento da Excelência Técnico-Gerencial;

- Programa Excelência Executiva, destinado ao aperfeiçoamento das competências estratégicas dos dirigentes da organização; 
- Outros eventos de atualização profissional - cursos, palestras e congressos diversos.

A fim de demonstrar o alcance da Universidade Corporativa junto aos empregados da Instituição, seguem as Tabelas 2, 3 e 4:

Tabela 2 - Bolsas de Graduação oferecidas pela UC Fonte: Site da Organização

\begin{tabular}{|c|c|}
\hline BOLSAS DE ESTUDO PARA CURSOS DE GRADUAÇÃO \\
\hline \multicolumn{1}{|c|}{ Período } & Número de Bolsas Concedidas \\
\hline 1997 & 3.000 \\
1998 & 1.000 \\
1999 & 1.000 \\
2000 & 1.000 \\
2001 & 1.000 \\
2002 & 1.812 \\
2003 & 1.752 \\
2004 & 3.311 \\
2005 & 3.306 \\
2006 & 1.200 \\
2007 & 500 \\
\hline TOTAL & $\mathbf{1 8 . 8 8 1}$ \\
\hline
\end{tabular}

Observa-se que o número de bolsas de graduação oferecidos de 1997 até 2007, perfazem um total de 18.881 alunos contemplados e que a média anual de concessão é de 1716 bolsas para curso superior.

Tabela 3 - Participantes do programa de aprimoramento

Fonte: Site da Organização

\begin{tabular}{|cc|}
\hline \multicolumn{2}{|c|}{ PROGRAMA EXTRAORDINÁRIO DE } \\
\multicolumn{2}{|c|}{ APRIMORAMENTO DOS FUNCIONÁRIOS } \\
\hline Ano & Funcionários atendidos \\
\hline 2003 & 47.943 \\
2004 & 47.642 \\
2005 & 50.154 \\
2006 & 52.215 \\
2007 & 49.907 \\
\hline
\end{tabular}

Pode-se verificar na Tabela 3 o elevado número de empregados atendidos pelo programa extraordinário de aprimoramento - foco principal da UC. Atualmente 
é obrigatório para os novos funcionários a entrada nesse Programa. Isso significa que o objetivo da organização é que todos os seus colaboradores façam parte desse programa que inclui desde o curso de formação inicial até, por exemplo, cursos avançados de Tecnologia da Informação e Finanças.

\begin{tabular}{|c|c|c|}
\hline \multicolumn{3}{|c|}{$\begin{array}{l}\text { NÚMERO DE TOTAL DE HORAS DE } \\
\text { TREINAMENTO E MÉDIA DE HORAS/AULA POR } \\
\text { FUNCIONÁRIO }\end{array}$} \\
\hline Ano & $\begin{array}{l}\text { Total de Horas de } \\
\text { Treinamento }\end{array}$ & $\begin{array}{c}\text { Média de Horas/Aula por } \\
\text { Funcionário }\end{array}$ \\
\hline 2000 & 7.167.619 & 91,66 \\
\hline 2001 & 6.095 .720 & 79,52 \\
\hline 2002 & 6.212 .760 & 80,42 \\
\hline 2003 & 6.886 .405 & 85,40 \\
\hline 2004 & 8.212 .417 & 100,28 \\
\hline 2005 & 11.130.108 & 132,26 \\
\hline 2006 & 12.717.516 & 153,83 \\
\hline 2007 & 15.011 .700 & 183,39 \\
\hline
\end{tabular}

Observa-se na Tabela 4 que a média de Horas/Aula por funcionário aumenta mais de $10 \%$ ao ano desde 2003 , o que demonstra que novos treinamentos estão sendo oferecidos e que os já existentes estão tendo a carga horária ampliada.

Percebe-se, após análise dos documentos disponibilizados pela organização, que a UC possui uma grande diversidade de cursos e treinamentos oferecidos aos seus alunos, e que o quantitativo de funcionários treinados é elevado quando comparado ao número total de colaboradores na organização.

\subsection{Resultados da aplicação dos questionários}

A pesquisa quantitativa abrangeu os empregados da agência bancária selecionada. A população dessa unidade atinge um total de 61 colaboradores. Foram distribuídos questionários em igual número, porém apenas 49 foram respondidos, o que equivale a $80,33 \%$ da população. O perfil demográfico dos respondentes será descrito a seguir. 
A) SEXO

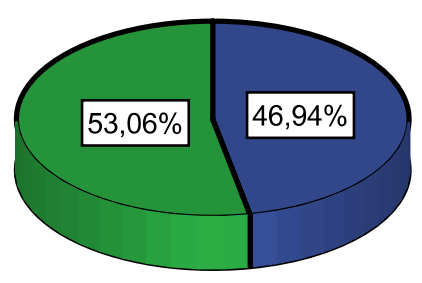

$\square$ Masculino

$\square$ Feminino

Gráfico 1 - Sexo dos Sujeitos da Pesquisa

Fonte: Próprio autor

Os dados do Gráfico 1 mostra que a maior parte dos integrantes são do sexo feminino $(53,06 \%)$.

B) FAIXA ETÁRIA

Tabela 5 - Faixa etária dos Sujeitos da pesquisa

Fonte: Próprio autor

\begin{tabular}{ccc}
\hline Faixa Etária & Freqüência & $\%$ \\
\hline 18 a 26 anos & 18 & 36,7 \\
\hline 27 a 34 anos & 18 & 36,7 \\
\hline 35 a 42 anos & 10 & 20,4 \\
\hline 43 a 50 anos & 3 & 6,20 \\
\hline- & 49 & 100
\end{tabular}

A Tabela 5 nos informa que $73,4 \%$ dos respondentes possuiam entre 18 e 34 anos e que a faixa etária entre 43 e 50 anos corresponde a apenas 6,20\%. 
C) NÍVEL DE ESCOLARIDADE

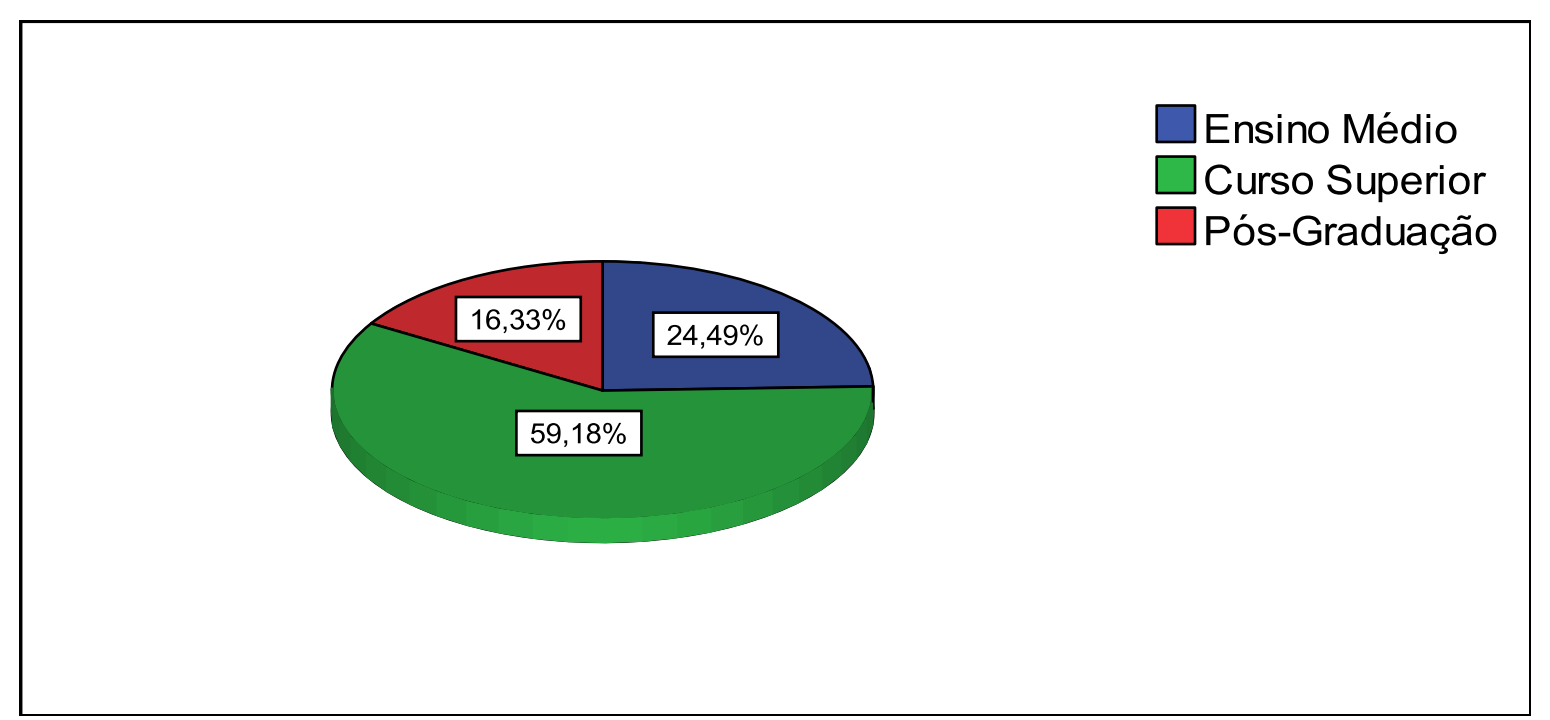

Gráfico 2 - Escolaridade dos sujeitos da pesquisa

Fonte: Próprio autor

O Gráfico 2 revela que $75,51 \%$ da amostra possuía formação superior ou Pós-Graduação e apenas 24,49 \% possuíam o requisito básico para se tornar empregado que é ter o Ensino médio completo.

D) CARGO OU FUNÇÃO OCUPADO

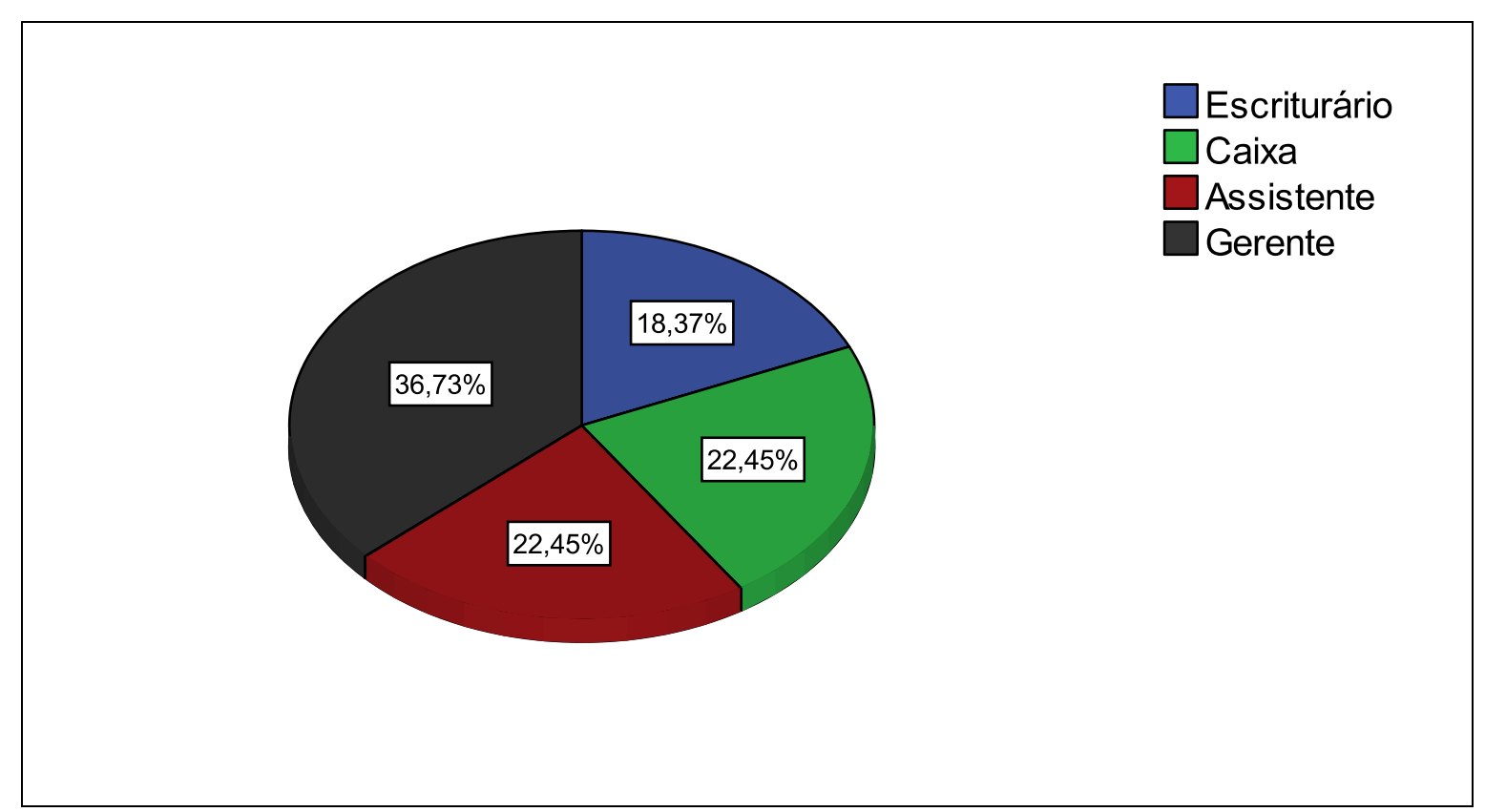

Gráfico 3 - Tipo de cargo/função dos sujeitos da pesquisa

Fonte: Próprio autor 
O Gráfico 3 mostra que 36,73\% dos respondentes faziam parte da gerência média ou superior e que $63,27 \%$ são escriturários, assistentes e caixas e estão subordinados aos gerentes. O que revela uma linha de comando com poucos funcionários para cada gerente.

E) TEMPO DE SERVIÇO NA OGRANIZAÇÃO

Tabela 6 - Tempo de serviço na organização dos sujeitos da pesquisa Fonte: Próprio autor

\begin{tabular}{ccc}
\hline Tempo de Serviço & Frequencia & $\%$ \\
\hline de 0 a 5 anos & 35 & 71,4 \\
\hline de 6 a 10 anos & 7 & 14,3 \\
\hline de 11 a 15 anos & 0 & 0 \\
\hline de 16 a 20 anos & 2 & 4,1 \\
\hline de 21 a 25 anos & 1 & 2 \\
\hline de 26 a 30 anos & 4 & 8,2 \\
\hline- & 49 & 100 \\
\hline
\end{tabular}

A Tabela 6 evidencia que a maioria dos participantes da pesquisa são empregados novos na organização, pois $71,4 \%$ deles tinham menos de 5 anos de tempo de serviço. Ao passo que apenas 14,3\% trabalhavam na empresa há mais de 15 anos. Porém, o tempo de serviço médio na organização era de 6 anos.

Por meio da estatística descritiva, mais especificamente média e desvio padrão dos fatores (grupo de perguntas) que compõem o instrumento, pode-se analisar a percepção dos colaboradores da organização acerca da UC. Segue abaixo a Tabela 7 referente essa análise.

Tabela 7 - Média e Desvio-Padrão dos Fatores do IMUC

Fonte: Próprio autor

\begin{tabular}{cccc}
\hline$N^{0}$ & Fator & Média & Desvio-Padrão \\
\hline 1 & Vinculação das ações educacionais às & 3,95 & 0,854 \\
estratégias da organização & & \\
\hline 2 & Estabelecimento das parcerias entre a & 3,21 & \\
\hline & organização e instituições de ensino & 0,921 \\
\hline 3 & Foco no modelo de gestão por competências & 3,82 & 0,894 \\
\hline & Aumento da visibilidade interna e externa da & 3,59 & \\
\hline
\end{tabular}




\begin{tabular}{llll}
\hline 5 & Estímulo a educação continuada & 3,82 & 0,891 \\
\hline
\end{tabular}

Na Tabela 7, encontra-se a fonte para a busca da resposta à pergunta do problema de pesquisa citado na introdução.

O questionário IMUC possui uma escala que vai de 1 que significa "discordo totalmente" até 5 , que significa "concordo totalmente". O número 3 tem significado de "em dúvida". Ou seja, respostas próximas ao número cinco representam que os colaboradores concordam com o benefício tragos pela UC.

A respeito do primeiro fator, percebe-se que os funcionários do Banco enxergam as ações educacionais viabilizadas pela UC como um instrumento para o alinhamento dos colaboradores com a estratégia da organização. Pode-se chegar a esse resultado pela média das respostas ser de 3,95, ou seja, significa a concordância dessa premissa citada diante de uma escala de 1 para discordo totalmente e 5 para concordo totalmente. Pode-se destacar a forte concordância dos respondentes na afirmação que "com a UC as ações educacionais contribuíram para a difusão da visão, missão e cultura da corporação". Esse fato pode ser explicado pela visão e a missão da corporação estar sempre presente nas páginas iniciais de todo material fornecido aos alunos e de todo curso auto-instrucional. Ressalta-se também, o baixo desvio-padrão apresentado, o que significa que houve poucas percepções divergentes acerca desse assunto.

O segundo fator trata de um dos braços da UC que é a parceria dessa com instituições tradicionais de ensino. Verificou-se que o resultado de 3,21 se aproxima muito da escala "em dúvida" do questionário, sendo de todos os fatores o que mais desabona o cumprimento dos objetivos da UC. Conforme entendimento dos colaboradores, não se verificou novas práticas ou idéias na organização em decorrência de parcerias com o meio acadêmico. Cumpre ressaltar que o item "Com a implantação da UC a interação com culturas diferentes (organização versus instituições de ensino superior) passou a ser mais constante" teve o nível de discordância mais alto de todo o questionário. O item "houve uma maior aproximação entre a organização e instituições de ensino" gerou um excesso de respostas "em dúvida" pelos participantes. Isso mostra que as parcerias com Faculdades e Universidades são desconhecidas pela grande maioria dos 
colaboradores e que correspondem a uma ação pouco desenvolvida na organização.

O desvio-padrão apresentado por esse segundo fator foi o mais alto dos cinco desvios estudados, atingindo o valor de 1,264. Demonstrando grande variabilidade de respostas dos sujeitos em relação ao fator.

O terceiro fator tem o foco no modelo de gestão por competências. Com esse busca-se saber se esse modelo possibilita a organização identificar e desenvolver as competências internas e externas necessárias a manutenção e ao destaque no mercado em que está inserida.

Diante dos resultados observa-se que os colaboradores concordam com essa assertiva, pois a média das respostas correspondeu ao valor de 3,82, com o desvio-padrão discreto.

O quarto fator envolve uma relação entre UC e Marketing, pois trata do aumento da visibilidade interna e externa da organização por meio dos treinamentos e outras ações promovidas pela UC junto aos colaboradores, empresas parceiras e comunidades onde estão localizadas.

Nesse fator o resultado da média foi de 3,59, ou seja, posicionado aproximadamente no meio entre "em dúvida" e "concordo pouco". No item "Com a implantação da UC, houve uma aproximação dos stakeholders e a organização com a melhoria da imagem da empresa" não houve nenhuma concordância por parte dos colaboradores. Esse fato nos leva a crer que a UC tem dispensado pouco esforço na busca de aproximação com clientes, fornecedores e comunidades.

O quinto e último fator trata do estímulo à educação continuada. Esse fator propõe que com a implantação da UC ampliaram-se as oportunidades de aprendizagem nas organizações, com apoio do ensino a distância por meio do uso de tecnologia da informação que expandiu e democratizou o ensino e a busca pelo conhecimento.

Diante da média de 3,82, verifica-se que os colaboradores concordaram com esse fator, especialmente no item "Com a implantação da UC, facilitou-se a difusão do conhecimento pela organização" que obteve média de 4,06.

Acredita-se que apesar de alguns itens mostrarem o não alcance dos objetivos da UC especialmente no que diz respeito à parceria com Instituições de ensino e de transmissão de conhecimento para agente externos à organização, fica claro que os colaboradores concordam de maneira geral que a UC gera uma 
vinculação entre os indivíduos e a estratégia organizacional, adota com sucesso o modelo de gestão por competências e cria um estimulo à educação continuada.

Foram calculadas correlações de Pearson entre os fatores do IMUC e as variáveis demográficas, a fim de verificar se havia relações entre essas variáveis. Foram calculadas correlações entre todos os fatores do questionário e todas as variáveis demográficas, porém não houve correlação signficativa.

Dengo (2001) ao ter como objetivo identificar e analisar algumas bases teórico-empíricas que buscam sustentar e divulgar a idéia de UC, por meio de estudos de caso em unidades brasileiras verificou, assim como o presente estudo fez nessa UC específica, que as UCs são unidades essencialmente internas de educação, ou seja, não atingem o objetivo de promover a disseminação do conhecimento junto aos clientes, fornecedores e outros stakeholders.

Dengo (2001) acrescenta, porém, que as UCs estão na maioria dos casos distantes da proposta teórica fundamentada pelos estudiosos do assunto e apresentam fortes características de modismo no campo da gestão. Esse as considera como positivas ao auxiliarem a divulgação da marca da empresa e por passarem a idéia de há utilização de um sistema inovador de gestão de pessoas.

Dengo (2001) conclui que o modelo tradicional de T\&D quando usado com novas tecnologias de aprendizagem e alinhado a estratégia organizacional cumpre o mesmo papel definido para as UCs.

Brandão (2006), ao pesquisar uma UC de uma Instituição Financeira por meio de um estudo de caso, obteve como resultados a necessidade de um aperfeiçoamento na articulação entre a área estratégica de Gestão de Pessoas e aqueles diretamente envolvidos nos programas de educação corporativa, pois segundo ela há um distanciamento entre o discurso gerencial e o que ocorre na prática. Essa considerou a implantação da UC como um processo evolucionário da tradicional área de T\&D, principalmente devido a sistematização da educação pelo incremento de metodologias e pelo forte uso de cursos a distancia.

Brandão (2006) ressalta, porém, que a percepção de valor gerado pela UC é mais evidente em funcionários em posição mais elevada na carreira em relação a colaboradores em nível essencialmente operacional.

Verificou-se ainda que a UC direciona boa parte de seus cursos para a cadeia de valor da organização, ou seja, há um foco maior no aprendizado das 
competências centrais (entenda-se mercado financeiro) e que gerem benesses negociais.

Silva (2006) aplicou o IMUC recém-validado na Universidade Corporativa do SESI com uma amostra composta por 302 profissionais. Tanto a média quanto o desvio-padrão apresentaram-se com comportamentos semelhantes aos observados no presente estudo, porém no trabalho desse autor o fator que obteve o maior grau de concordância por parte dos participantes foi o de estímulo à educação continuada.

Cumpre mostrar que os colaboradores avaliaram a UC daquela organização com níveis de concordância levemente superiores ao verificado na Instituição Financeira em questão. Já os níveis de Desvio-Padrão na Instituição financeira foram maiores, ou seja, houve nos resultados do Banco uma maior divergência de concepções dos respondentes.

No trabalho de Silva (2006) também não foram encontrados correlações significativas entre a análise fatorial e as variáveis demográficas. 


\section{CONSIDERAÇÕES FINAIS}

O presente trabalho objetivou avaliar o funcionamento da Universidade Corporativa de uma Instituição Financeira por meio da percepção dos seus colaboradores e da análise do que a alta administração deseja obter com a UC, ou seja, houve a intenção de verificar se os funcionários da unidade organizacional estudada enxergam a UC de maneira semelhante ao qual é proposta pela área de Gestão de Pessoas da organização, que é a encarregada da formulação de normas e diretrizes para Universidade.

Outro objetivo foi o de promover uma revisão na literatura nacional sobre os temas de Educação Corporativa e Universidade Corporativa, onde foi observado que, apesar do crescente número de UC's no país, existem ainda poucos estudos sobre o assunto e que sua maioria se concentra no campo das definições e conceitos.

Em consonância com o referencial teórico e com os resultados da análise documental, verificou-se que a importância de se ter um quadro de pessoal qualificado e capaz de agir corretamente em tempos de rápidas mudanças no mercado fez com que a organização em questão criasse uma UC que atendesse grande parte de seus funcionários, conforme verificado no quantitativo de carga horária de treinamento por pessoa em um ano.

Conclui-se que a UC em análise, conforme resultados obtidos por meio da aplicação do questionário IMUC, cumpre boa parte do que propõe em seu site e nos demais materiais analisados, especialmente no que diz respeito aos tópicos relacionados a "criar uma base corporativa de conhecimentos que assegura a competitividade da organização", "estimular a organização de espaços educativos em todas as unidades do Banco", "ampliar a comunidade de aprendizagem" e "democratizar o acesso ao conhecimento por meio de recursos de educação a distância".

Acredita-se que a Universidade Corporativa dessa organização em questão, não se constitui como um modismo gerencial, pois há nessa empresa um sistema formal de educação corporativa desde 1965, com posterior evolução a UC desde 2002 e pelo fato da organização ter um quantitativo tão expressivo de alunos inseridos nos programas de aprimoramento. Não há que se falar nesse caso concreto que essa UC tem o intuito apenas de fortalecer sua marca internamente 
quando se possui tamanha capacidade estrutural e de profissionais para multiplicação do conhecimento, conforme verificado na análise documental desse trabalho.

Pode-se concluir ainda que a UC necessita de ações que desenvolvam mais o fator estabelecimento de parcerias com instituições de ensino, uma vez que a relação com essas estimularia a geração de idéias na organização por meio de trocas de experiências com o meio acadêmico.

Esse trabalho teve como principal contribuição a análise, por meio dos seus usuários, das ações de uma Universidade Corporativa, porém essa pesquisa apresenta limitações e uma delas é o fato dos questionários serem aplicados apenas em uma unidade federativa, sendo que o Banco encontra-se situado em todas as regiões do país. Outra limitação é o número reduzido de questionários aplicados e o fato de ele atingir apenas um tipo de unidade organizacional, as agencias bancárias. Cabe ressaltar que existem ainda na estrutura da empresa, unidades regionais, superintendências, unidades de apoio às agências, além das diretorias e vicepresidências situadas na sede.

Sugere-se para futuros estudos na área de Educação Corporativa e Universidade Corporativas, a verificação dos resultados encontrados em organizações com características diferentes da estudada, que hajam estudos com um número maior de indivíduos e localidades e com mais tipos distintos de unidades organizacionais presentes e que haja uma pesquisa qualitativa após a obtenção dos resultados pelo questionário IMUC para um aprofundamento das razões de não percepção das ações de uma Universidade Corporativa. 


\section{REFERÊNCIAS}

ALPERSTEDT, C. Universidades corporativas: discussão e proposta de uma definição. RAC - Revista de Administração Contemporânea, v. 5, n. 3, set./dez. 2001.

As universidades corporativas no contexto do ensino superior. Publicação da Faculdade de Economia, Administração e Contabilidade da Universidade de São Paulo, 2001.

Banco do Brasil. Sobre a Universidade Corporativa. Disponível em http://www44.bb.com.br/appbb/portal/bb/unv/sobre/index.jsp. Acesso em: $12 \mathrm{de}$ junho de 2009.

BRANDÃO, G.R. Gestão de Pessoas e as Universidades Corporativas: Dois lados da Mesma Moeda? RAE - Revista de Administração de Empresas, São Paulo: v. 46, n. 2, 2006.

CARVALHO, R. P. Universidade corporativa: uma nova estratégia para a aprendizagem organizacional. Santa Catarina, 2001. Dissertação (Mestrado em Engenharia da Produção) - Programa de Pós- Graduação em Engenharia da Produção da UFSC. Disponível em: http://teses.eps.ufsc.br/defesa/pdf/5559.pdf

DENGO, N. Universidades corporativas: modismo ou inovação?. In: ENCONTRO NACIONAL DA ASSOCIAÇÃO NACIONAL DOA PROGRAMAS DE PÓSGRADUAÇÃO E PESQUISA EM ADMINISTRAÇÃO, 26º 2002, Salvador. ENANPAD. Rio de Janeiro: Metrópole, 2002

EBOLI, M. P. Universidade Corporativa: ameaça ou oportunidade para as escolas tradicionais de administração? RAUSP - Revista de Administração da Universidade de São Paulo. São Paulo: v. 34, n. 4,1999. p. 56-64.

2004.

. Educação corporativa no Brasil: mitos e verdades. São Paulo: Gente,

GHEDINE, T.; FREITAS, H. A utilização da Educação à Distância via Internet em uma Universidade Corporativa: um estudo exploratório. São Paulo/SP: XXXVII ENANPAD, CD, Set. 2003.

IBGE. Pesquisa Nacional por Amostra de Domicílios. 2007. Disponível em http://www.ibge.gov.br/brasil_em_sintese/default.htm. Acesso em: 12 de junho de 2009.

MALVEZZI, S. Do taylorismo ao comportamentalismo: 90 anos de desenvolvimento de recursos humanos. In: BOOG, G. G. Manual de Treinamento e Desenvolvimento. São Paulo: Makron Books, 1999. p. 15-34.

MEISTER, J. C. Educação corporativa: a gestão do capital intelectual através das universidades corporativas. São Paulo: Makron Books, 1999. 
PONTUAL, C. Evolução do treinamento empresarial. In: BOOG, G. (Coord.) Manual de Treinamento e Desenvolvimento. São Paulo: McGraw-Hill, 1980. p. 1-12.

RAPOSO, M. Aprendizagem Organizacional como fator de insitucionalização na Universidade Corporativa da Inústria da Paraíba- UCIP. Brasília: 2006

SENGE, P.M. A quinta disciplina: arte e prática da organização que aprende. São Paulo: Best Seller, 1998.

SILVA, R.C.J. Construção e Validação de Escala de Medida de Mudança Organizacional Causada pela Implantação de uma Universidade Corporativa. Dissertação (Mestrado em Gestão Social e Trabalho) - Faculdade de Economia, Administração, Contabilidade e Ciência da Informação e Documentação da Universidade de Brasília, Brasília, 2006.

TARAPANOFF, K. Panorama da educação corporativa no contexto internacional. In: Educação Corporativa - contribuição para competitividade. Brasília: MDIC, 2004.

TOLEDO, F. ; MILIONE, B. Dicionário de recursos humanos. São Paulo: Atlas, 1996.

VARGAS, M. R.; ABBAD, G. S. Bases conceituais em treinamento, desenvolvimento e educação - TD\&E. In: BORGES-ANDRADE; ABBAD, G. S..; MOURÃO, L. (Org.).Treinamento, desenvolvimento e educação em organizações e trabalho: fundamento para a gestão de pessoas. Porto Alegre: Artmed, 2006.

VERGARA, S. C. Projetos e Relatórios de pesquisa em administração. 3 ed. São Paulo: Atlas, 2000.

- Motivos para a Criação da Universidade Corporativa. Revista de Administração Mackenzie. São Paulo, ano 3, n. 2, p 79-98, ago. 2002.

VIEIRA, A; GARCIA, F. Gestão do conhecimento e das competências gerenciais: um estudo de caso na indústria automobílistica. RAE - Revista de Administração de Empresas. São Paulo, v.3 n.1, Art 6, jan./jun. 2004

VITELLI, A. P. D. Universidades Corporativas: fonte de vantagem competitiva para as organizações na era do conhecimento? Trabalho apresentado no Encontro Nacional da Associação Nacional dos Programas de Pós-graduação e Pesquisa em Administração (ANPAD). Anais. Campinas: 2000. 


\section{ANEXO A}

Esta pesquisa faz parte da monografia final da Graduação em Administração na Universidade de Brasília cujo tema versa sobre a percepção dos colaboradores acerca de sua Universidade Corporativa.

Peço a sua contribuição para responder a este questionário. Não há respostas certas ou erradas, o importante é que a sua opinião seja sincera. As respostas serão analisadas de modo a não identificar os respondentes.

Agradeço antecipadamente pela colaboração.

Alexandre Mattos de Freitas - alexandrefreitas adm@yahoo.com.br

Telefone: 8171-0255

Responda às frases conforme escala a seguir:

\begin{tabular}{|c|c|c|c|c|}
\hline $\begin{array}{c}1 \text { - Discordo } \\
\text { Totalmente }\end{array}$ & $\begin{array}{c}2 \text { - Discordo } \\
\text { pouco }\end{array}$ & 3 - Em dúvida & $\begin{array}{c}4 \text { - Concordo } \\
\text { pouco }\end{array}$ & $\begin{array}{c}5 \text { - Concordo } \\
\text { totalmente }\end{array}$ \\
\hline
\end{tabular}

\section{Com a implantação da Universidade Corporativa...}

\begin{tabular}{|c|c|c|c|c|c|c|}
\hline Item & & 1 & 2 & 3 & 4 & 5 \\
\hline 01 & $\begin{array}{l}\text { estimulou-se a cultura do autodesenvolvimento como forma de se buscar o permanente } \\
\text { crescimento profissional. }\end{array}$ & & & & & \\
\hline 02 & facilitou-se a difusão do conhecimento por toda a Organização. & & & & & \\
\hline 03 & $\begin{array}{l}\text { aprimorou-se a capacidade de negociação com parceiros dada a visibilidade que a Organização } \\
\text { assumiu no meio externo. }\end{array}$ & & & & & \\
\hline 04 & o desenvolvimento de competências internas à Organização ganhou maior destaque. & & & & & \\
\hline 05 & $\begin{array}{l}\text { ampliou-se a interação com instituições de ensino contribuindo para as ações educacionais } \\
\text { desenvolvidas na Organização. }\end{array}$ & & & & & \\
\hline 06 & as ações educacionais passaram a ajudar a Organização a atingir sua missão. & & & & & \\
\hline 07 & $\begin{array}{l}\text { foram estimuladas novas idéias a partir do conhecimento adquirido nos contatos com o meio } \\
\text { acadêmico. }\end{array}$ & & & & & \\
\hline 08 & as ações educacionais contribuíram para a difusão da visão, missão e cultura da corporação. & & & & & \\
\hline 09 & $\begin{array}{l}\text { passou-se a utilizar o modelo de gestão de pessoas que possibilita a identificação de } \\
\text { competências a serem desenvolvidas nos profissionais de acordo com as estratégias da } \\
\text { Organização. }\end{array}$ & & & & & \\
\hline 10 & $\begin{array}{l}\text { ampliou-se o acesso aos cursos a distância, com utilização do espaço web contribuindo para o } \\
\text { contínuo processo de educação dos empregados. }\end{array}$ & & & & & \\
\hline 11 & ampliaram-se os canais de comunicação entre os colaboradores da Organização. & & & & & \\
\hline 12 & $\begin{array}{l}\text { houve uma maior aproximação entre stakeholders (clientes, fornecedores, empregados, etc) e a } \\
\text { Organização trazendo uma melhoria da imagem da Empresa. }\end{array}$ & & & & & \\
\hline 13 & $\begin{array}{l}\text { passou a existir uma maior contribuição para a aprendizagem organizacional a partir da troca de } \\
\text { experiências com as instituições de ensino superior. }\end{array}$ & & & & & \\
\hline 14 & $\begin{array}{l}\text { ampliaram-se as oportunidades de aprendizagem na Organização reforçando a idéia de educação } \\
\text { permanente. }\end{array}$ & & & & & \\
\hline 15 & a formação de profissionais passou a ser feita de acordo com as estratégias organizacionais. & & & & & \\
\hline 16 & houve uma maior contribuição para a aquisição de competências emergentes pela Organização. & & & & & \\
\hline 17 & as ações educacionais passaram a atender às estratégias empresariais. & & & & & \\
\hline
\end{tabular}




\begin{tabular}{|c|c|c|c|c|}
\hline $\begin{array}{c}1 \text { - Discordo } \\
\text { Totalmente }\end{array}$ & $\begin{array}{c}2 \text { - Discordo } \\
\text { pouco }\end{array}$ & 3 - Em dúvida & $\begin{array}{c}4 \text { - Concordo } \\
\text { pouco }\end{array}$ & $\begin{array}{c}5 \text { - Concordo } 49 \\
\text { totalmente }\end{array}$ \\
\hline
\end{tabular}

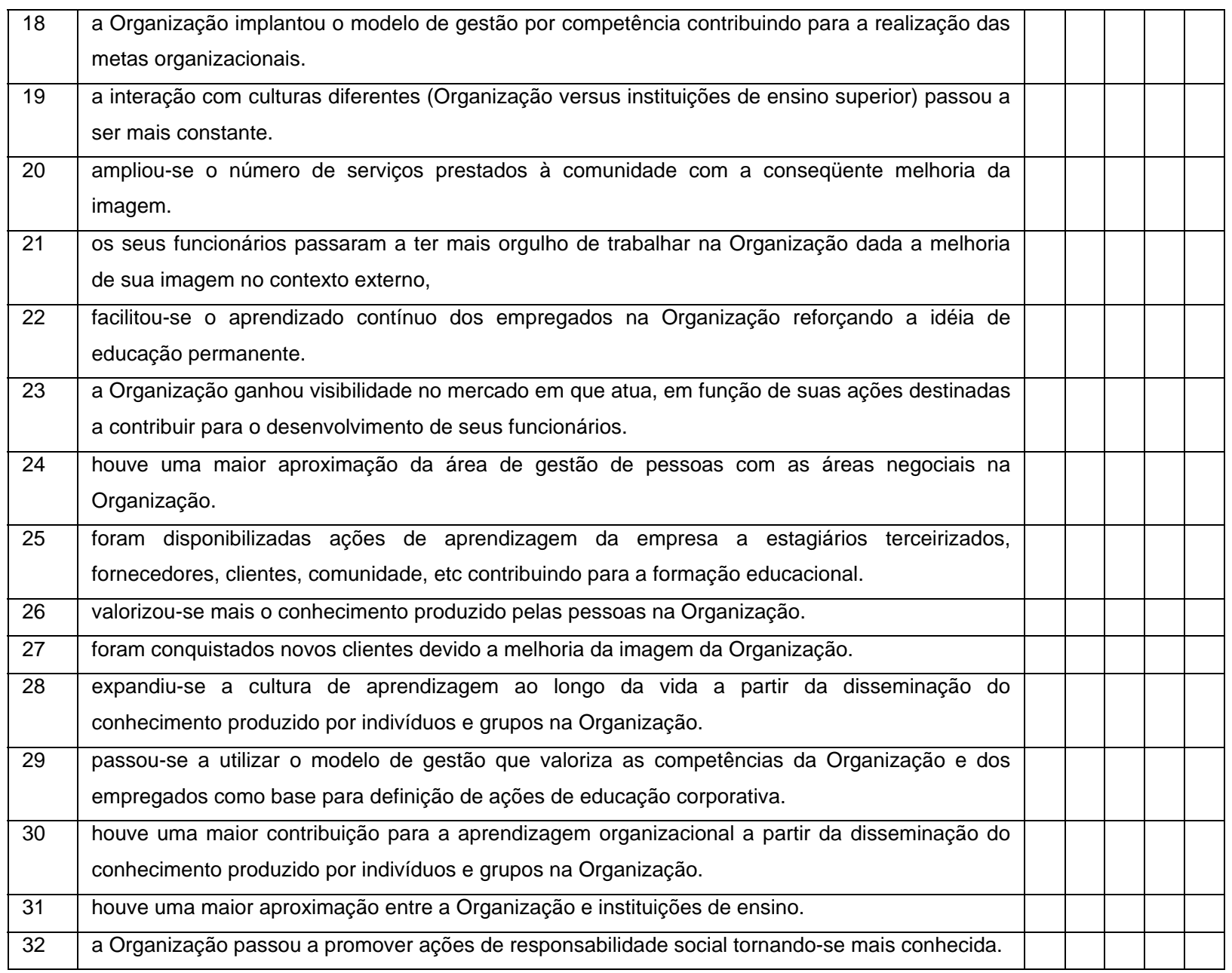

Instrumento de Mudança Organizacional provocada pelas Universidades Corporativas, Silva (2006).

Para finalizar, pedimos responder alguns itens com o objetivo de caracterizar os participantes da pesquisa. Muito Obrigado.

1- Sexo: a- ( ) Masculino b- ( ) Feminino

2- Idade: anos

3- Escolaridade: a- ( ) Ensino médio b- ( ) Curso Superior c- ( ) Pós-graduação

4- Cargo/ função: a- ( ) Escriturário b- ( ) Caixa c- ( ) Assistente d- ( ) Gerente

5- Tempo de serviço na organização: anos.

Caso deseje acrescentar alguma informação sobre a Universidade Corporativa, utilize o espaço a seguir. 